\title{
Selection and Ranking of the Most Suitable Drones for Sustainable Traffic Management Using Multi- Criteria Analysis Approach
}

\author{
Mustafa Hamurcu \\ Kırıkkale University
}

Tamer EREN ( $\nabla$ tamereren@gmail.com )

Kırıkkale Üniversitesi: Kirikkale Universitesi https://orcid.org/0000-0001-5282-3138

\section{Research Article}

Keywords: drones, decision making, sustainable traffic management

Posted Date: November 11th, 2021

DOl: https://doi.org/10.21203/rs.3.rs-999357/v1

License: (c) (1) This work is licensed under a Creative Commons Attribution 4.0 International License.

Read Full License 


\title{
Selection and Ranking of the Most Suitable Drones for Sustainable Traffic Management using Multi-criteria Analysis Approach
}

\author{
Mustafa Hamurcu ${ }^{1}$ and Tamer Eren $^{2 *}$
}

${ }^{1}$ Kırıkkale University, Department of Industrial Engineering, Faculty of Engineering and Architecture, 71451, Kırıkkale, Turkey hamurcu.mustafa@kku.edu.tr

${ }^{2 *}$ Kirıkkale University, Department of Industrial Engineering, Faculty of Engineering and Architecture, 71451, Kırıkkale, Turkey

tamereren@gmail.com, +90 3183574242/1050

* Corresponding Author

\begin{abstract}
The traffic problem is one of the significant issues facing many large cities. So, transportation plans should be analyzed very well. Static cameras are tools and the right solution for traffic monitoring and management. But, nowadays, drones come into prominence as popular, effective, and more sustainable tools in traffic control and have been used for various traffic applications. In this study, a model is proposed for the selection of the most suitable drone under the specific characteristics to ensure a contributor to traffic management efforts. The decision model is structured with AHP and MOORA-TOPSIS and VIKOR ranking methods. The weighting of criteria is carried out by the AHP method, and a combination of AHP and ranking methods are used for the best selection. The results of the analysis were compared using Spearman's rank correlation, and it is seen that the results are at the desired level.
\end{abstract}

Keywords: drones, decision making, sustainable traffic management

\section{Introduction}

The world population in urban areas will be more increas according to United Nations reports (Un, 2014). Cities will be more crowded and extensive. The world population estimated for 2050 will increased from the current $54 \%$ to nearly $66 \%$. In recent years, the growth of cities due to a high population density have being become more and more serious, causing the new challenges in the management of limited resources. One of these challenges also is traffic control and monitoring. In this point, improvement of the life quality is main aim in urban areas in terms of security, travelling time, speed. All of these factors are necessitate the applications such as data collection and processing, information discovery and visualization, events prediction or emergencies detection (Garcia-Aunon et al., 2019). 
The management of ever-increasing traffic volumes and congestion levels is one of the most critical challenges faced by many cities. These problems further have become an important particularly at metropolitan areas. So, it has become critical to monitor and analyse the state of traffic flow at urban transportation. However, there are only limited viable options like manual counters, static video camera systems, manned vehicles and air vehicles for control of all these situations. Thus, transportation planners and managers have been searching new solutions and these solutions should be ensure an accurate, dynamic, and quick inflow of traffic data (Khan et al., 2017).

Sustainable transportation is identified by many researchers. Black (1997) and Richardson (1999) defined as "A sustainable transportation system has been defined as one that satisfies current transport and mobility needs without compromising the ability of future generations to meet their own." Also, sustainable traffic system management under the many factors of environmental, economic, social, safety and flexibility, is a responsible and complex task. Under the current situations, the collection of high quality and real time data to support their traffic control activities have become more complicated taking also into consideration that traditional methods are usually costly, lengthy, limited to specific areas and the data have poor quality. In recent years, drones come into prominence among the alternative traffic control tools for traffic management and control activities for the increase of the reliability and effectiveness of transportation systems in its many activities.

Current used control tools are an expensive and difficult process due to requires a large number of installed sensors or equipment. Besides, a high number of deployed staff and fixed sensors are needed in order to cover the entire network (Coifman, et al., 2006), but these is not practically possible solutions (Puri, 2005). Acquiring and processing video streams from employee in charge, static cameras and manned air vehicles has been used and proposed as the most efficient tools for visualizing and gathering traffic information. Hence, conventional control tools are not sustainable in terms of economic, social and environmental. However, sustainability is very important notion in today like in transportation planning processes. To provide continuance of traffic surveillance and monitoring is just as basis as setting transportation systems or construction up. Besides, the main element of activity of traffic managment has been traffic surveillance and monitoring that is one of the important tools and strategies for years (Papageorgiou et al., 2008). Hence, drones play a significant role for transportation in providing services to promote sustainable development in usage of limited resources. In addition, traffic monitoring is a critical subject to smart cities and sustainability. In the future, monitoring to improve smarter cities is basic issues to usage of public spaces and environmental sustainabiliy (Garcia-Aunon et al., 2019).

Another alternative for traffic data collection is the air vehicles with remote sensing. Manned air vehicles were used for data collection over the years. This alternative is also not sustainable due to cost and deployment issues restrict. The use of UAVs/drones have emerged in the field of traffic surveillance and monitoring due to the increased needs in dealing with congestion more effectively and directly with the latest advances in technology. So, recently, unmanned aerial systems have started to be used and improved for traffic monitoring, management, and control (Puri, 2005; Kanistras, et al., 2015). UAVs have some advantage in comparison with static cameras and manned air vehicles. Length coverage, multiple uses, energy efficiency, video post-processing 
skills, data transfer, communication and storage are high; Operation skills, training requirement, complexity, risk are medium level; endurance, deployment, operational time, operation under adverse weather, security/privacy and cost (acquiring and maintenance) are lower than others (Barmpounakis et al., 2016). Usage of the UAV technology for collection of detailed and accurate traffic data in traffic have gain speed due to video quality, low cost, the mobility and flexibility of the system (Khan, et al., 2017).

This is why drones have been regarded as convenient solutions for providing lower cost and maximum flexibility in traffic control and management applications. The widespread use of drones, therefore, will play a vital role in preventing traffic accidents, accident involving death and providing of drivers attentions in traffic. Besides, these applications prevent to risk life of traffic control officials. So, drone applications are important tools to provide the sustainable traffic control and management.

Urban areas are in need of the applications of control by drone for supporting sustainable traffic management due to some main reasons:

- Using static control tools in relatively low-density areas is usually cost-inefficient. In this point, drones present wide range of an application.

- Using drones provide flexibility in the traffic control applications and have lower risk according to other tools as manned control tools and static control tools.

- Many cities and city management have limited financial resources to invest in advanced traffic monitoring and management systems.

- Drones have cost-efficient both purchase and setup and operation according to their alternatives.

Recently, drones have been begun to adopt in traffic control and manegment such as many area. Besides, the drone market and drone technology are increasing and improving day by day and this rising is still continuing exponentially. Notwithstanding, although it has seen improved in the drone technology, technology forecasts suggest that the diffusion of drones is not matured. This process will be more continue with technological development.So, it is needed decision making process for the most suitable dorne selection for traffic control and management. Moreover, selecting the best drone for traffic control and management is a great challenge and influenced by a number of conflicting factors including charging time, flight time, camera, flight distance, flight speed, weight and price and so on. In this respect, using MCDM methods can be a good solution for this multi factor problem. Keeping in mind the these all situations, this study specifically presents a specific, reliable, and understandable decision process for traffic managers in this sense. $\mathrm{UAVs} /$ Drones have been developed to their special characteristics with the latest advances in technology. Today, there are many drone vehicles models and manufacturers that are present in market with different combinations. Many manufacturers have been continued rapidly to the development studies on drones for better performance. The selection of the most suitable drone vehicle is a key issue to effective of use of resources and to ensure sustainability. This decision making process is usually based on complicate procedure due to many evaluation criteria and alternatives. MCDM methods, AHP, TOPSIS, MOORA, VIKOR, can help to decision makers for complex decision process in solving their problems, especially regarding sustainable traffic 
monitoring tools to deal with this challenge. Hence, this study proposes a decision-making process under the special criteria upon which to focus. Because evaluation criteria weights directly influence the overall results, they take on an important role in the decision making process. AHP, one of the MCDM methods, is an important tool in this point. Besides, it is needed to apply objective weighting methods such as TOPSIS, VIKOR and MOORA so on to get more powerful rankings. But, MCDM methods can give diverse ranking results due to its different analytic decision process. This case can leads to inconsistency problems in the decision-making process. Thus, To validate the various ranking results, therefore, it has been made Spearman' rank correlation coefficient and sensitive analyse of result ranking. Many studies have applied the MCDM models in the current literature to provide solutions for achieving sustainable transportation solution and mitigating environmental problems, e.g. electric bus selection for green transportation, sustainable urban transportation alternatives, evaluation of urban mobility projects, sustainable transportation planning strategies, performance of alternative vehicle technologies, implementing clean energy and alternative-fuel technology selection, etc. (Onat et al., 2016; Oztaysi et al., 2017; Nassereddine and Eskandari, 2017; Büyüközkan et al., 2018; Awasthi et al., 2018; Wann-Ming and Jhong-You, 2018; Li et al., 2019; Sałabun et al., 2019; Hamurcu and Eren, 2020a; Hamurcu and Eren, 2020b). However, we have met any research about selection of drone by using MCDM in transportation monitoring, though there are many studies about implementation and usage of UAVs/drones at various areas (Khan et al., 2018; Xu et al., 2014; Tores et al., 2016; Gago et al., 2015; Mohamed et al., 2018). The purpose of this study is to present the combined MCDM model for drone selection.

The rest of the paper is organized as follows: Section 2 provides literature review about transportation and UAV/drones and overview of use of drone for traffic monitoring. Besides it discusses some potential applications. Section 3 description of MCDM problem. Section 4 explain briefly MCDM methods, AHP, TOPSIS; MOORA and VIKOR. Section 5 do an application for selection process and be presented respectively definition of alternatives and criteria, and problem structure. Section 6 discusses the potential results and useful of employing MCDM methods in decision process. Besides, sensitivity analysis of results is made and give limitation of the study. Section 7 concludes the paper.

\section{Literature review}

\subsection{Transportation planning}

Traffic control is an important activity minimum as far as transport planning. So, traffic control activities should be without interruption to ensure traffic security and interflow of traffic. One of the major problems facing many large cities is transportation.

One of the most important task of transportation planners is to ensure the traffic flow and mobility. Many problems have surface in transportation in real-life; some of them, traffic congestion, insufficient infrastructure, increasing travel time, increasing the number of automobiles and other some reasons etc. All this traffic problem has been cause to search of the new and effective solutions. Planners also try new ways for solution of traffic congestion and many projects for improve the traffic are presented by planners. To collect the real-time information from traffic is a very hard work. So, Mohamed et al (2020) have said that "Todays, drones are seen as the most 
suitable solution about this subject in terms of ensure the collect and deliver a complete set of realtime information about traffic congestions". We also deal with usage of drone in traffic monitoring in this study.

In addition to, several approaches were developed that offer different types of effective and efficient decision making process to improve the transportation. for example; evaluation studies (Nassereddine and Eskandari, 2017; Mavi et al., 2018; Rajak et al., 2016; Kim et al., 2017; Broniewicz and Ogrodnik, 2020), selection processes (Buwana et al., 2016; Büyüközkan et al., 2018; Deveci et al., 2018; Żak, 2017) and optimization applications (Yu et al., 2018; Levi et al., 2019; Doğan and Akgüngör, 2016).

Besides, many researchers use MCDM methods for solution of transportation problems. For example; Hamurcu and Eren (2020) used AHP-TOPSIS for electric bus selection. And in other their study (2020), they used same method for strategic planning for transportation. Alkharabsheh et al. (2021) evaluated urban public transportation systems using MCDM. Sarkar and Biswas (2021) used MCDM under the uncertainty. They used AHP-TOPSIS integrated approach for transportation management. Broniewicz and Ogrodnik (2020) used MCDM for analysis of transport infrastructure projects. Bakioglu and Atahan (2021) applied AHP integrated TOPSIS and VIKOR methods with Pythagorean fuzzy sets to prioritize risks in self-driving vehicles.

\subsection{Drones}

With the passage of time, UAVs/Drones gained popularity in many areas worldwide. Development process of drones that beginning with military and defence applications continues with many civil applications, and has be more grown rapidly. Use of drones have been increase to aims of like traffic surveillance, infrastructure inspection and law enforcement (Saeed et al., 2018).

Drones have important advantages, especially fast, cost-effective and risk according to regular manned airplanes or helicopters for various applications, (For example; reaching places that are difficult to access, doing dangerous tasks). At the same time, drones are more effective and flexible also according to other traffic monitoring tools.

Unmanned Aerial Vehicles (UAVs), popularly known as drones that were initially utilized for military applications (Al-Madani et al., 2018). But in today, UAVs/drones have become widespread and they have been used in many civil areas (Ham, et al., 2016) such as agriculture (Honkavaara et al., 2013; Kim et al., 2019), logistics (Raj and Sah, 2019), environmental protection (Wivou et al., 2016), public safety (De Melo et al., 2017), tourism support (Stankov et al., 2019), health emergency services (Kim et al., 2017; Ullah, et al., 2019), large-scale disaster management (Luo, 2019; Li et al., 2011).; Estes, 2014).; Tuna et al., 2014; d'Oleire-Oltmanns et al., 2012), infrastructure inspections (Mota et al., 2014; Deng et al., 2014), traffic monitoring and management ( İn table x), military mission (Jenkins, 2012; Yakıc1, 2016) and civil engineering(Liu et al., 2014; Yang et al., 2015; Y1ldızel and Çalış, 2019). Besides, UAV technology promising to provide new opportunities in also smart applications (Mohamed et al., 2018; Hamurcu and Eren, 2019)

\subsection{A brief overview of existing research on traffic surveillance}




\begin{tabular}{|c|c|c|c|c|}
\hline Reference & UAV/Drone applications & MCDM & Optimization & $\begin{array}{c}\text { Not } \\
\text { analyzed }\end{array}$ \\
\hline $\begin{array}{l}\text { Barmpounakis and Geroliminis, } \\
2020\end{array}$ & Urban traffic monitoring & & & $\mathrm{x}$ \\
\hline Ryan et al. 2020 & Driver performance & & & $\mathrm{x}$ \\
\hline Lucic et al. 2020 & Dynamic Planning & & & \\
\hline Freeman et al. 2019 & Vehicle stacking estimation & & & $\mathrm{x}$ \\
\hline Elloumi et al. 2019 & Traffic monitoring & & & $\mathrm{x}$ \\
\hline Ray and Sah, 2019 & Logistics sector & $\begin{array}{l}\text { Grey- } \\
\text { DEMATEL }\end{array}$ & & \\
\hline Sreenath and Panda, 2019 & $\begin{array}{l}\text { Traffic Counting-Turning } \\
\text { Fraction Estimation }\end{array}$ & & & \\
\hline Khan et al. 2018 & Traffic analysis & & & $\mathrm{x}$ \\
\hline Congress et al. 2018 & $\begin{array}{l}\text { Monitoring transportation } \\
\text { infrastructure }\end{array}$ & & & $\mathrm{x}$ \\
\hline Khan et al., 2018 & Traffic Analysis & & & $\mathrm{x}$ \\
\hline Li et al., 2018 & Traffic monitoring & & Scheduling & \\
\hline Ke et al., 2018 & $\begin{array}{l}\text { Traffic flow parameter } \\
\text { estimation }\end{array}$ & & & \\
\hline Bertrand et al., 2018 & Evaluating Risk & & & \\
\hline Sutheerakul et al., 2017 & Traffic monitoring & & & $\mathrm{x}$ \\
\hline Barmpounakis et al., 2016 & Transportation engineering & & & $\mathrm{x}$ \\
\hline Chow, 2016 & Traffic monitoring & & & $\mathrm{x}$ \\
\hline Reshma et al., 2016 & Traffic monitoring & & & \\
\hline Salvo et al., 2014 & Traffic analysis & & & $\mathrm{x}$ \\
\hline
\end{tabular}

Drones are flexible and fast vehicles that can be used for many applications in transportation. These include traffic and crowd monitoring, traffic control (see Table 1).

Table 1. A brief overview of literature

Besides, the most comprehensive study on drone selection has been done by Nur et al. (2020). Their study's aim is to use interval -valued inferential fuzzy TOPSIS for the last mile delivery drone selection. Four main criteria were used in their studies. These main criteria and subcriteria respectively; Physical specification (drone overall size, weight, drone type, fuel type), performance (internal computing components, location and proximity accuracy, communication and data quality, traceability, reliability), economic (repair cost, total unit cost, total life cost, operating cost, training cost), environmental (adaptability, recharge/refuel location, environmental impact, required delivery distance) and payload capacity (max flight time, charge/fuel usage rate, maximum load, maximum carry dimensions, maximum reachable altitude, drone speed, adaptability to dynamic assignment, package handling flexibility, delivery flexibility). Finally, the most suitable drone for last mile delivery were selected among the four drone alternatives (small quadcopter, larger quadcopter, tilt wing, fixed wing). Similarly, another a study was made by Hamurcu and Eren (2020) about unmanned aerial vehicles, using AHP and TOPSIS methods. They used MCDM under the specific criteria to select the best unmanned aerial vehicle for defence area. However, none of the studies listed above sought to selection of drones for traffic monitoring and control using MCDM based on a standardized framework. Specifically, the objectives of this study are to: 
1. To determine the weight of factors affecting drone selection

2. To emphasis to the importance of sustainable traffic control and monitoring tools

Table 2. Comparative perf

\begin{tabular}{|c|c|c|c|c|c|}
\hline Method & Computational time & Simplicity & $\begin{array}{l}\text { Mathematical } \\
\text { calculations }\end{array}$ & Stability & Information type \\
\hline AHP & Very high & Very critical & Maximum & Poor & Mixed \\
\hline TOPSIS & Moderate & $\begin{array}{c}\text { Moderately } \\
\text { critical }\end{array}$ & Moderate & Medium & Quantitative \\
\hline
\end{tabular}




\begin{tabular}{cccccc} 
MOORA & Very low & Very simple & Minimum & Good & Quantitative \\
VIKOR & Less & Simple & Moderate & Medium & Quantitative \\
\hline
\end{tabular}
follows.

The calculation steps of the TOPSIS, MOORA and VIKOR are presented respectively in

\subsection{AHP method (Analytic Hierarchy Process)}

The AHP, proposed by Saaty in 1971, is well known and the most widely method used for handling MCDM problems. The AHP based on pairwise comparison and a nine-point scale to ascertain the priority of the elements considered (Saaty, 2008). In this study, the briefly basic analytic process of the AHP methodology are as follows:

-To structure complex decisions as a hierarchy of goals and criteria.

-To conduct a pairwise comparison of each criterion in the hierarchy. Note that AHP was applied in this study to calculate the weights of the evaluation criteria based on expert opinion.

-Finding of the maximum eigenvalue $\left(\left(\lambda_{\max }\right)\right.$, consistency index (with (1) and consistency ratio (CR) (with (2)) for examining the consistency of the judgments and conducting a consequence weight analysis

$C I=\frac{\left(\lambda_{\max }-n\right)}{(n-1)}$

$C R=\frac{C I}{R I}$

The number 0.1 is the accepted upper limit in the control of CR value. It means logically feasible of the pairwise comparisons results (Saaty, 2008). Otherwise, If the final consistency ratio exceeds this value, the decision-making process has to be repeated to ensure consistency. The measurement of consistency uses to evaluate both the consistency of decision-makers and the consistency of overall hierarchy (Wang \& Yang, 2007).

In this study, the AHP is used to determine weights of the evaluation criteria of drone selection problem. Ranking methods are used to obtain final selection.

\subsection{TOPSIS}

TOPSIS method was proposed by Hwang and Yoon in 1981 and it is a useful tool in solving complicated decision-making problems. (Hwang and Yoon, 1981). In this method, the points are important that are the shortest distance from the ideal solution and the farthest distance from the negative ideal solution. The TOPSIS method ensure and aim to minimize distance among two points. It makes ranking among alternatives and chooses the nearest alternative to the ideal solution (Özcan et al., 2017).

The relative distance of each alternative that are the ideal point $d_{i}^{+}$and negative ideal point $d_{i}^{-}$calculated as follows respectively: 
$288 d_{i}^{+}=\left\{\sum_{j=1}^{n}\left(w_{j} *\left(r_{i j}-r_{j}^{+}\right)\right)^{2}\right\}^{\frac{1}{2}}$

$289 \quad d_{i}^{-}=\left\{\sum_{j=1}^{n}\left(w_{j} *\left(r_{i j}-r_{j}^{-}\right)\right)^{2}\right\}^{\frac{1}{2}}$

(wj : the weight of criterion; $\mathrm{j}$ : rij: the vector normalization: $\mathrm{i}$ in relation to criterion $\mathrm{j} ; r_{j}^{+}$:

$\mathrm{j}$-th coordinate of the ideal point; $\mathrm{n}$ : the number of criteria; $r_{j}^{-}: \mathrm{j}$-th coordinate of the negative ideal 292 point)

After that, in the next step, by calculating C+ values with Eq (5), the ranking of alternatives is determined (where $0 \leq \mathrm{Ci} \leq 1$ ). The best alternatives are ranked in the based on the highest $\mathrm{Ci}$ 295 value.

$296 \quad C_{i}=\frac{d_{i}^{-}}{d_{i}^{+}+d_{i}^{-}}$

The positive ideal and negative ideal points in TOPSIS method are determined using Eq (5) and $\mathrm{Eq}(7)$ as follows:

$$
\begin{aligned}
& A^{+}=\left\{r_{1}^{+}, r_{2}^{+}, \ldots, r_{n}^{+}\right\}=\left\{\left(\max _{i} r_{i j} \mid j \in I_{\text {max }}\right), \quad\left(\min _{i} r_{i j} \mid j \in I_{\text {min }}\right)\right\} \\
& A^{-}=\left\{r_{1}^{-}, r_{2}^{-}, \ldots, r_{n}^{-}\right\}=\left\{\left(\min _{i} r_{i j} \mid j \in I_{\text {max }}\right), \quad\left(\max _{i} r_{i j} \mid j \in I_{\text {min }}\right)\right\}
\end{aligned}
$$

where $I_{\max }$ : set of the benefit criteria and $I_{\min }$ : set of the cost criteria. Finally, it should be noted that TOPSIS method uses vector normalization procedure with Eq (8), as follows:

$$
r_{i j}=\frac{x_{i j}}{\left(\sum_{i=1}^{m} x_{i j}^{2}\right)^{\frac{1}{2}}}
$$

(The established matrix consists of $m$ alternatives and $n$ criteria with the intersection of each alternative and criteria given as xij).

\subsection{MOORA method}

MOORA, in the multi objective optimization, on the basis of ratio analysis method, uses both beneficial and cost criteria in ranking of the alternatives. MOORA is the one of developed MCDM method in recently. This method presents a statistical decision making process for selecting the best alternative among the possible alternatives (Brauers and Zavadskas, 2006).

$$
r_{i j}=\frac{x_{i j}}{\left(\sum_{i=1}^{m} x_{i j}^{2}\right)^{1 / 2}}, i=1,2, \ldots, m ; j=1,2, \ldots, n
$$

This method starts with establish a decision matrix consisting of problem alternatives with respect to evaluation criteria. Then the decision matrix is normalized (rij: the normalized situation of ith alternative on jth criteria)) as Eq. (8) (Patel and Maniya, 2015). Weighted normalized 
$317 \quad y_{i}=\sum_{j=1}^{g} w_{j} r_{i j}-\sum_{j=g+1}^{n} w_{j} r_{i j}$

$338 x_{j}^{*}= \begin{cases}\max _{j} x_{i j} & j \in I_{\max } \\ \min _{j} x_{i j} & j \in I_{\min }\end{cases}$

339

340

\subsection{VIKOR method} problems (Opricovic, 1998).

$Q_{i}=v \frac{\left(S_{i}-S^{*}\right)}{\left(S^{-}-S^{*}\right)}+(1-v) \frac{\left(R_{i}-R^{*}\right)}{\left(R^{*}-R^{*}\right)}$

$$
S_{i}=\sum \frac{w_{j}\left(x_{j}^{*}-x_{i j}\right)}{\left(x_{j}^{*}-x_{j}^{-}\right)}
$$

and

$$
R_{i}=\max _{j}\left[w_{j}\left(x_{j}^{*}-x_{i j}\right) /\left(x_{j}^{*}-x_{j}^{-}\right]\right.
$$

$$
x_{j}^{*}= \begin{cases}\min _{j} x_{i j} & j \in I_{\max } \\ \max _{j} x_{i j} & j \in I_{\min }\end{cases}
$$

decision matrix is formed. $\mathrm{Wj}$ in the $\mathrm{Eq}(10)$ donets the weight of the $\mathrm{jth}$ criterion. These wj values can be found using MCDM methods like the AHP method.

The highest $\mathrm{yi}^{*}$ value is the best alternatives in the ranking of the alternatives. Ranking of all the alternatives are obtained with descending order of yi* values.

In 1998, VIKOR method was proposed by Opricovic. Decision process is based on the particular measure of 'closeness' to the 'ideal' solution. This method based on distance-to-target MCDM methodologies is used in many different areas and enjoys a wide acceptance at the decision

The best alternative in decision process with VIKOR is determined on the basis of the overall ranking index (Qi), which is determined as follows with Eq (10):

where $\mathrm{Si}$ and $\mathrm{Ri}$ are the average and the worst group score of alternative $\mathrm{i}$.

$$
S^{*}=\min _{i} S_{i}, S^{-}=\max _{i} S_{i}, R^{*}=\min _{i} R_{i}, R^{-}=\max _{i} S_{i}, \quad \text { and } \quad \mathrm{v} \text { represents a }
$$

significance of the strategy, which value is usually set to be 0.5 . The average score $\mathrm{Si}$ and the worst group score $\mathrm{Ri}$ for each alternative are determined as follows:

where $\mathrm{p}$ is a parameter; $\mathrm{p} \in[1, \infty)$ and $x_{j}^{*}$ and $x_{j}^{-}$are determined as follows:

\section{The decision problem: Selection of Drone for Sustainable Traffic Management}




\subsection{Alternatives definition}

Twelve alternatives were determinate by expert team. The features of these alternatives are shown in Table 3. And definitions are follows;

Alternative D_1: This model presents a good performance with 12MP camera, 23-minute flight time and lower price.

Alternative D_2: Featuring a 1-inch CMOS sensor that can shoot 4K/60fps videos and 20MP photos, this model grants users absolute creative freedom. This model presents a complete aerial imaging solution with $20 \mathrm{MP}$ camera. While a wide array of intelligent features makes flying that much easier, has additional safety applications. Technical properties are 66-minute charging time, 30-minute flight time, 4.3 miles' flight distance $45 \mathrm{mhp}$ speed.

Alternative $D \_3$ : This drone has a dedicated flight camera and has super lightweight design.

Alternative $D \_4$ : This model has very good an image processing system. Its main feature is maximum speed that is $58 \mathrm{MP}$. This model is different with other drones in this size in terms of this feature. Besides, it goes from 0 to $50 \mathrm{mph}(80 \mathrm{mph})$ in 5 seconds and has a max descent speed of $9 \mathrm{~m} / \mathrm{s}$. It also can fly low temperature thanks to self-heating technology and has maximum of 27 minutes' flight time with a dual battery system.

Alternative D_5: this model has a 12 MP camera. It has more sensitive CMOS lens than any other known drone camera, allowing you to get great videos with 1080pl. Drone weight is 300 grams and flight time is 16 minute and speed is $50 \mathrm{~km}$.

Alternative D_6: This model is a small yet powerful drone, has a $4 \mathrm{~K}$ camera stabilized by a 3-axis mechanical gimbal. It has 12MP camera, 60-minute charging time, 27-minute flight time, 4.3 miles range, $40 \mathrm{mph}$ speed and high-performance computing cores. Besides, 5 vision sensors are among the its important features.

Alternative D_7: It has features high-end flight performance and functionality. It's some feature are ultraportable with 430 grams' weight and foldable, 21-minute max flight time, 55minute charging time, $13 \mathrm{MP}$ camera. Besides This model is one of the cheaper than other models.

Alternative $D_{-}$8: The compact powerful this model has a simplified flying experience and a perspective unlike any other. This model has features such as Ultra-light (249 g); 30-min Max. Flight Time, 4 km HD Video Transmission, 3-Axis Gimbal 2.7K Camera.

Alternative D_9: This model has 2x Optical Zoom Camera and 31-min Max. Flight Time and Omnidirectional Obstacle Sensing system.

Alternative D_10: It is one of the latest drone of the generation and the most advanced with 30 minutes' battery life and a new flight assistance system. D_10 model can fly up to $60 \mathrm{~km} / \mathrm{h}$ with new propulsion system. One of the important specification of this model also is range of up to 2 $\mathrm{km}$ thanks to the Wi-Fi HD 720p transmission system. 
Alternative D_11: This alternative drone can capture unseen and ultra-stable images from new angles and has camera that can tilt $180^{\circ}$ vertically with up to lossless zoom and an image stabilization system.

Alternative D_12: This model ensures a good performance for easy-to-fly, has 25-minute flight time and 35 miles' flight distance. It has excellent video quality with $4 \mathrm{~K}$ camera and 3 -axis gimbal. This model can keep the itself safe and stable in challenging situations thanks to the Star Point Positioning System, and exclusive SecureFly technology.

Table 3. Alternative drones

\begin{tabular}{cccccccc}
\hline Model & $\begin{array}{c}\text { Camera } \\
\text { (MP) }\end{array}$ & $\begin{array}{c}\text { Charging } \\
\text { time }\end{array}$ & $\begin{array}{c}\text { Flight Time } \\
\text { (minutes) }\end{array}$ & $\begin{array}{c}\text { Flight } \\
\text { Distance } \\
\text { (miles) }\end{array}$ & $\begin{array}{c}\text { Flight Speed } \\
(\mathrm{mph})\end{array}$ & $\begin{array}{c}\text { Weight } \\
\text { (grams) }\end{array}$ & $\begin{array}{c}\text { Approximate } \\
\text { Price }(\$)\end{array}$ \\
\hline D_1 & 12 & 96 & 23 & 3.1 & 38.5 & 1280 & 800 \\
D_2 & 20 & 66 & 30 & 4.3 & 45 & 1390 & 1400 \\
D_3 & 16 & 90 & 15 & 3.1 & 40 & 3500 & 3000 \\
D_4 & 20 & 90 & 27 & 4.3 & 58 & 4000 & 4900 \\
D_5 & 12 & 120 & 16 & 1.2 & 31 & 300 & 550 \\
D_6 & 12 & 60 & 27 & 4.3 & 40 & 730 & 700 \\
D_7 & 12 & 55 & 21 & 2.4 & 42 & 430 & 800 \\
D_8 & 12 & 270 & 30 & 2.5 & 29 & 249 & 399 \\
D_9 & 12 & 90 & 31 & 11.2 & 44.7 & 905 & 1439 \\
D_10 & 14 & 110 & 30 & 1.2 & 40 & 525 & 600 \\
D_11 & 21 & 120 & 25 & 2.5 & 33 & 320 & 699 \\
D_12 & 12 & 110 & 25 & 1.2 & 35 & 1600 & 1600 \\
\hline
\end{tabular}

\subsection{Criteria definition}

Criterion C1: Camera (MP): This criterion is main element for traffic control and monitoring. We use as alternative the camera drones in this study. Camera drone is use for the purposes of filming, photography, inspection, surveying, and video.

Criterion C2: Charging time(minute): It is time that it takes for the battery to fully charge. It may not be required for certain missions. But it is an important factor under the limited resources.

Criterion C3: Flight Time (minutes): The maximum time that a drone stays in the air on a full battery. This criterion is relevant since the duration of the operating capacity at the traffic control time depend on it. Control distance is important for remote controlled flying devices. Its battery capacity and the range of the flight increase with together the developing technology. Hence, tasks time of drone is increasing and so these can use in longer time tasks.

Criterion C4: Flight Distance (miles): The control distance air to surface is important factor in management and control of drone. it is demand to be the maximum of it.

Criterion C5: Flight Speed (mph): It is possible to this criterion that to define as the maximum speed at which a drone can perform a given mission without jeopardizing its integrity. Because, some missions demand high speeds at traffic while some traffic monitoring missions do not require such high speeds. 
419

\section{0}

Criterion C6: Weight (g): The maximum weight at which a drone is utility and transposability. This criterion is important for user traffic personnel.

Criterion C7: Approximate Price (\$): This criterion presents an economically. This is a critical factor to ensure of effective usage of limited sources.

\subsection{Problem structure}

\subsubsection{Determination of the weight of the criteria}

A group of expert helped to us for evaluation of criteria that are an industrial engineering, an electric-electronic engineering, and four academics about transportation planning. To determine the weights of the evaluation criteria is necessary to establish a pairwise comparison process between each criterion. AHP method use Saaty 1-9 scale for this process. The pairwise comparison matrix established via expert opinions is shown in Table 4. In result of the comparison, calculate consistency ratio $(\mathrm{CR})$ is $0,07532(<0,1)$. So, consistency of pairwise comparisons is in suitable and reliable value.

Table 4. Weights of criteria by using AHP through experts

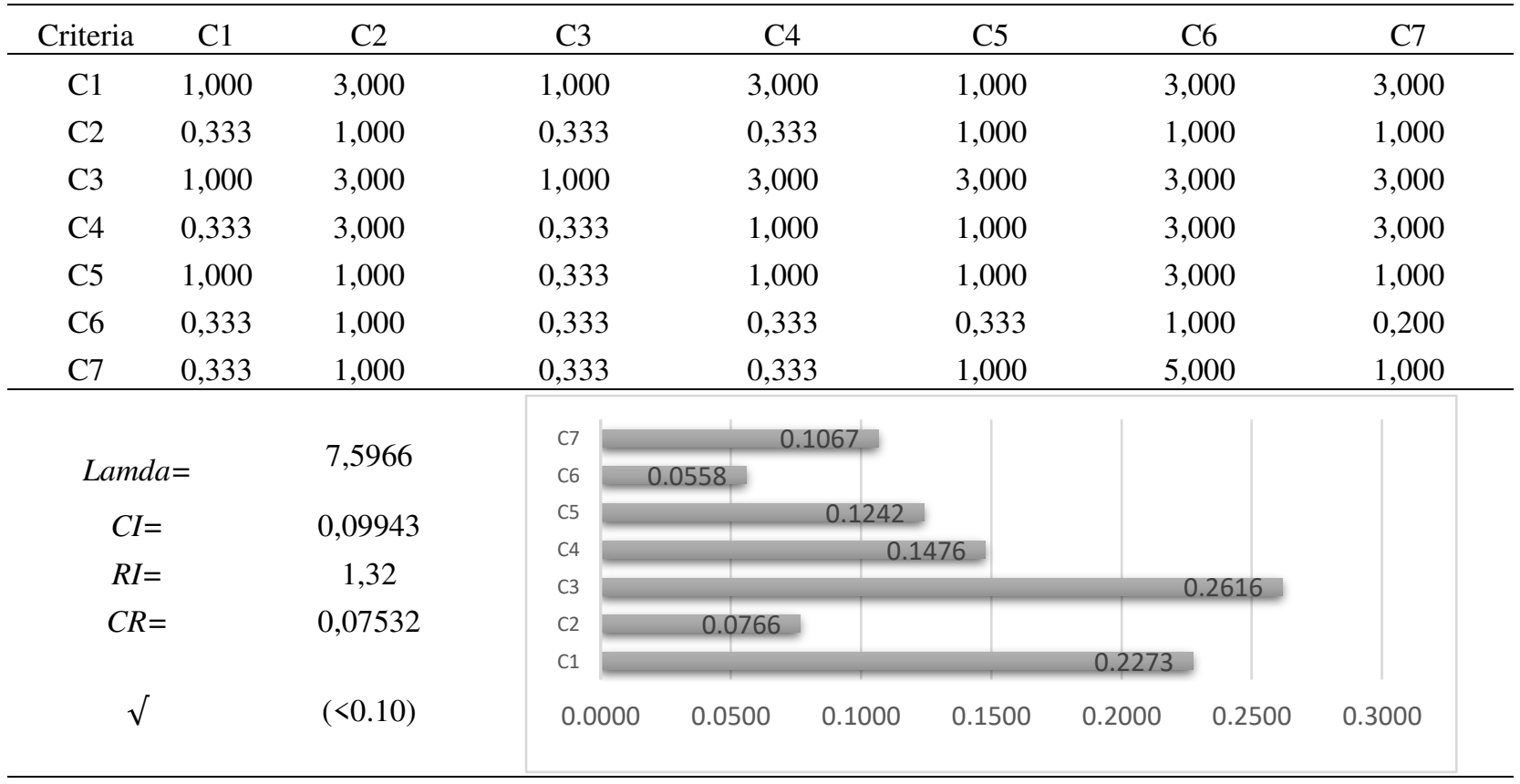

According to the above results, flight time (C3) $(0,2616)$ is the most important criterion, followed by camera (c1) (0,2273), flight distance (C4) (0,1476), flight speed (C5) $(0,1242)$, approximate price (C7) $(0,1067)$, and charging time (C2), and weight (C6) $(0,0558)$, respectively. Flight time and camera are the most important two factors for traffic monitoring and control.

\subsubsection{Ranking of the alternatives}

Having obtained the weights for decision variables using the AHP method, the ranking process will be continue using MOORA, TOPIS and VIKOR methods. 


\subsubsection{MOORA results}

431

432

433

434

435

436

437

438

439

440

441

442

443

444

445

446

Drone selection problem was first solved by using MOORA method. The normalization decision matrix established by using Eq. (8). The weighted ranking values (yi) found for alternatives by using Eq. (9) is shown in Table 5. As it can be seen, the first rank is D_9 with 0,2462 value. Which has the highest yi value.

Table 5. Weighted ranking values (yi) with MOORA

\begin{tabular}{cccccccccc}
\hline \multirow{2}{*}{ Normz. } & C1 & C2 & C3 & C4 & C5 & C6 & C7 & \multirow{2}{*}{ yi } & \multirow{2}{*}{ Rank } \\
\cline { 2 - 6 } D_1 & 0,0525 & 0,0178 & 0,0680 & 0,0307 & 0,0342 & 0,0118 & 0,0131 & 0,1427 & 7 \\
D_2 & 0,0875 & 0,0123 & 0,0888 & 0,0425 & 0,0400 & 0,0129 & 0,0229 & 0,2108 & 2 \\
D_3 & 0,0700 & 0,0167 & 0,0444 & 0,0307 & 0,0355 & 0,0324 & 0,0490 & 0,0825 & 12 \\
D_4 & 0,0875 & 0,0167 & 0,0799 & 0,0425 & 0,0515 & 0,0370 & 0,0800 & 0,1277 & 9 \\
D_5 & 0,0525 & 0,0223 & 0,0473 & 0,0119 & 0,0275 & 0,0028 & 0,0090 & 0,1052 & 11 \\
D_6 & 0,0525 & 0,0111 & 0,0799 & 0,0425 & 0,0355 & 0,0068 & 0,0114 & 0,1811 & 4 \\
D_7 & 0,0525 & 0,0102 & 0,0621 & 0,0237 & 0,0373 & 0,0040 & 0,0131 & 0,1484 & 6 \\
D_8 & 0,0525 & 0,0501 & 0,0888 & 0,0247 & 0,0258 & 0,0023 & 0,0065 & 0,1328 & 8 \\
D_9 & 0,0525 & 0,0167 & 0,0917 & 0,1108 & 0,0397 & 0,0084 & 0,0235 & 0,2462 & 1 \\
D_10 & 0,0612 & 0,0204 & 0,0888 & 0,0119 & 0,0355 & 0,0049 & 0,0098 & 0,1623 & 5 \\
D_11 & 0,0919 & 0,0223 & 0,0740 & 0,0247 & 0,0293 & 0,0030 & 0,0114 & 0,1832 & 3 \\
D_12 & 0,0525 & 0,0204 & 0,0740 & 0,0119 & 0,0311 & 0,0148 & 0,0261 & 0,1081 & 10 \\
\hline
\end{tabular}

\subsubsection{TOPSIS results}

In the application of the TOPSIS method the decision matrix is established by using Eq (7). The pozitie ideal and negative ideal solution, determinated by Eq. (5) and Eq (6). Ideal solution (Ci) is calculated with the distances from the ideal ( $\mathrm{Si}+$ ) and negative ideal solution ( $\mathrm{Si}-$ ) by using Eq (3), (4) and Eq (5). Ci values and TOPSIS rank are present in Table 6. The best drone among the alternatives is D_9 in TOPSIS method. The ranking of others is D_2, D_6, D_11, D_10, D_1, D_7, D_8, D_5, D_12, D_3, and D_4 respectively.

Table 6. Weighted ranking (Ci) with TOPSIS

\begin{tabular}{ccccc}
\hline Alternatife & A+ & A- & Ci & Rank \\
\hline D_1 & 0,0950 & 0,1215 & 0,561 & 6 \\
D_2 & 0,0721 & 0,1102 & 0,604 & 2 \\
D_3 & 0,1102 & 0,0954 & 0,464 & 11 \\
D_4 & 0,1071 & 0,0879 & 0,451 & 12 \\
D_5 & 0,1185 & 0,1354 & 0,533 & 9 \\
D_6 & 0,0816 & 0,1213 & 0,598 & 3 \\
D_7 & 0,1013 & 0,1294 & 0,561 & 7 \\
D_8 & 0,1059 & 0,1324 & 0,556 & 8 \\
D_9 & 0,0454 & 0,0955 & 0,678 & 1 \\
\hline
\end{tabular}




\begin{tabular}{llllc}
\hline D_10 & 0,1054 & 0,1401 & 0,571 & 5 \\
D_11 & 0,0916 & 0,1222 & 0,572 & 4 \\
D_12 & 0,1128 & 0,1285 & 0,533 & 10 \\
\hline
\end{tabular}

\subsubsection{VIKOR results}

The similar evaluations are performed by using VIKOR method. The overall ranking index Qi obtained by Eq. (10), as well as the ranking order of considered alternatives are also shown in Table 7. Si and Ri values are found by using Eq (11) and Eq (12) based on Eq (13) and Eq (14) İn Qi calculation. Partial ranking results achieved using the VIKOR method are shown in Table 7. The best alternative in VIKOR method in 0,5 value is $\mathrm{D} \_2$.

Table 7. Weighted ranking (Qi) with VIKOR

\begin{tabular}{ccccc}
\hline Alternatives & $\mathrm{Sj}$ & $\mathrm{Rj}$ & $\mathrm{Qj}$ & Rank \\
\hline D_1 & 0,6007 & 0,2273 & 0,7362 & 7 \\
D_2 & 0,2438 & 0,1019 & 0,0000 & 1 \\
D_3 & 0,7071 & 0,2616 & 0,9458 & 11 \\
D_4 & 0,3675 & 0,1067 & 0,1342 & 2 \\
D_5 & 0,7634 & 0,2453 & 0,9488 & 12 \\
D_6 & 0,4878 & 0,2273 & 0,6275 & 6 \\
D_7 & 0,6015 & 0,2273 & 0,7369 & 10 \\
D_8 & 0,5730 & 0,2273 & 0,7095 & 9 \\
D_9 & 0,3312 & 0,2273 & 0,4768 & 5 \\
D_10 & 0,4464 & 0,1768 & 0,4295 & 4 \\
D_11 & 0,3650 & 0,1285 & 0,1998 & 3 \\
D_12 & 0,6398 & 0,2273 & 0,7737 & 8 \\
\hline
\end{tabular}

\section{Result and discussion}

In this section three ranking methods are compared. Similarities of their results are analysed and verification of the results without AHP are made. This section, the answer is searced to the question of whether the proposed model produced reliable results. Three MCDM method's results are compared as this quastion's answer. The consolidated results gained by ranking methods, TOPSIS, VIKOR and MOORA, and analyse is shown in Table 8 . The reasons for selecting these three ranking methods for decision process and comparison are simplicity( basic mathematica calculations), ease of use for users, adaptation to real decision problems.

\subsection{Comparing the MCDM methods and variation of the ranking}

In this section, MCDM methods are compared to each other and analysed to variation of the results. Table 8 and Fig. 1show the rankings of all the alternative drones using the three MCDM methods. D_9 is in the first rank at MOORA and TOPSIS methods. But it is in fifth rank at VIKOR method. D_2 is the first rank in the VIKOR method. Drone D_2 is also in second rank other two MCDM methods. The worst alternative also is D_3 at the MOORA; D_4 at the TOPSIS and D_5 at the VIKOR method. 
471 Spearman' rank correlation coefficient $\left(r_{s}=\left[\frac{6 * \sum_{j=1}^{K}\left(d_{k}\right)^{2}}{K *\left(K^{2}-1\right)^{2}}\right]\right.$, di: symbolizes the ranking 472 difference of drone $\mathrm{j})$ and statistical significant value $\left(Z=r_{s} * \sqrt{(K-1)}, \mathrm{K}\right.$ is the number of drone) 473 are used for methods' results. The rating scores of the three MCDM methods application are then 474 compared with the ones obtained using method results via Spearman's rank correlation test and 475 shown in Table 8. In our study, 1.645 is selected as the critical $Z$ value at the level of significance 476 of $\alpha=0.05$. Since $Z$ value (3.1079) at the MOORA and TOPIS are higher than 1.645, it can be 477 stated that is statistically similar among each other. At the same time $z$ value $(2,2265)$ at the 478 MOORA and VIKOR are higher than 1.645. So it is statistically similar among each other. But 479 TOPSIS and VIKOR rank are not statistically similar due to Z value is lower than 1.645.

480 Table 8. Comparison of drone ranking approaches and Spearman' rank correlation coefficient

\begin{tabular}{cccccccccc}
\hline \multirow{2}{*}{ Alternative } & \multicolumn{2}{c}{ MOORA (A) } & \multicolumn{2}{c}{ TOPSIS (B) } & \multicolumn{2}{c}{ VIKOR (C) } & \multicolumn{3}{c}{ Ranking differences(d) } \\
\cline { 2 - 10 } & yi & Rank & Ci & Rank & Qi & Rank & A-B & A-C & B-C \\
\hline D_1 & 0,1427 & 7 & 0,561 & 6 & 0,7362 & 7 & 1 & 0 & -1 \\
D_2 & 0,2108 & 2 & 0,604 & 2 & 0,0000 & 1 & 0 & 1 & 1 \\
D_3 & 0,0825 & 12 & 0,464 & 11 & 0,9458 & 11 & 1 & 1 & 0 \\
D_4 & 0,1277 & 9 & 0,451 & 12 & 0,1342 & 2 & -3 & 7 & 10 \\
D_5 & 0,1052 & 11 & 0,533 & 9 & 0,9488 & 12 & 2 & -1 & -3 \\
D_6 & 0,1811 & 4 & 0,598 & 3 & 0,6275 & 6 & 1 & -2 & -3 \\
D_7 & 0,1484 & 6 & 0,561 & 7 & 0,7369 & 10 & -1 & -4 & -3 \\
D_8 & 0,1328 & 8 & 0,556 & 8 & 0,7095 & 9 & 0 & -1 & -1 \\
D_9 & 0,2462 & 1 & 0,678 & 1 & 0,4768 & 5 & 0 & -4 & -4 \\
D_10 & 0,1623 & 5 & 0,571 & 5 & 0,4295 & 4 & 0 & 1 & 1 \\
D_11 & 0,1832 & 3 & 0,572 & 4 & 0,1998 & 3 & -1 & 0 & 1 \\
D_12 & 0,1081 & 10 & 0,533 & 10 & 0,7737 & 8 & 0 & 2 & 2 \\
\hline & \multicolumn{1}{c}{ rs } & & & & 0,9371 & 0,6713 & 0,4685 \\
& & & Z & & & & & & \\
\end{tabular}

481

482

483

484

485

486

487

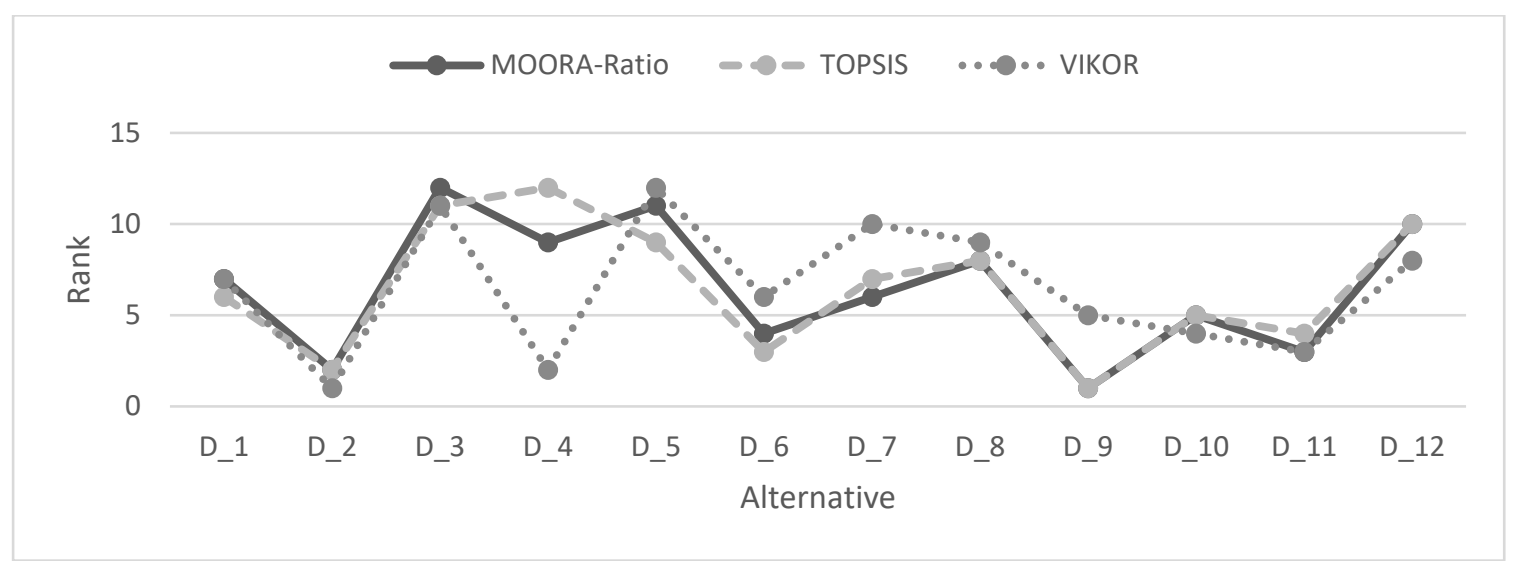

Fig. 1. Comparing of MCDM results

\subsection{Sensitivity analysis}

We used unweighted MOORA-TOPSIS and VIKOR methods without AHP for sensitive analysed and then statistically similarity test is made. The ranking scores of methods and 
spearman's rank correlation test of method results are shown in Table 9. The best drone was not also change at each three methods. However, it had been seen some difference the ranking scores. Besides, each three method ranking have be statistically similar. Thereby, we can understand that usage of AHP is affected ranking of results.

Table 9. Variation of the ranking with unweighted methods

\begin{tabular}{|c|c|c|c|c|c|c|}
\hline Alternatives & $\operatorname{MOORA}(\mathrm{A})$ & TOPSIS(B) & VIKOR(C) & A-B & $\mathrm{A}-\mathrm{C}$ & B-C \\
\hline D_1 & 7 & 6 & 8 & 1 & -1 & -2 \\
\hline D_2 & 3 & 3 & 1 & 0 & 2 & 2 \\
\hline D_3 & 12 & 11 & 12 & 1 & 0 & -1 \\
\hline D_4 & 11 & 12 & 7 & -1 & 4 & 5 \\
\hline D_5 & 8 & 8 & 11 & 0 & -3 & -3 \\
\hline D_6 & 2 & 2 & 4 & 0 & -2 & -2 \\
\hline D_7 & 5 & 4 & 6 & 1 & -1 & -2 \\
\hline D_8 & 9 & 9 & 9 & 0 & 0 & 0 \\
\hline D_9 & 1 & 1 & 3 & 0 & -2 & -2 \\
\hline D_10 & 6 & 7 & 5 & -1 & 1 & 2 \\
\hline D_11 & 4 & 5 & 2 & -1 & 2 & 3 \\
\hline D_12 & 10 & 10 & 10 & 0 & 0 & 0 \\
\hline \multirow{2}{*}{\multicolumn{4}{|c|}{$\begin{array}{l}\text { rs } \\
Z\end{array}$}} & 0,9790 & 0,8462 & 0,7622 \\
\hline & \multicolumn{3}{|c|}{$\mathrm{Z}$} & 3,2470 & 2,8064 & 2,5281 \\
\hline
\end{tabular}

\subsection{Limitation of the study}

The aim of this work is the selection of the best drone among several alternatives found on the current drone market. Drones have many various specifications and there are various drone models and firms in drone market. But we determinated only twelve drones in this study as alternatives according to expert opinions. Used drones in this study are small type and have short flight time. These drones can be used by each traffic control personals. So, these drones have been using to small mission and application in the traffic monitoring and control. Hence, there are industrial drones for biggest tasks such as usage in the metropolitan. Industrial drones are more professional and need speciality. This study limited in terms of alternatives. Besides, one of the important conditions that limit this study is adverse weather conditions such as wind and precipitation. In this study, adverse weather conditions are not taken into account. In future studies, resistance to bad weather conditions can be considered as a criterion.

\section{Conclusion}

Traffic monitoring and control are important subject for adaption to sustainable transportation, especially in economic development. This study presents a hybrid MCDM model to selection of among the sustainable traffic monitoring tools, drones. The model includes two main steps: finding the priority weight derived by the AHP, ranking the drone alternatives using the three MCDM methods, MOORA, TOPSIS and VIKOR to select an optimal drone for traffic control in the sustainable transportation. The main contribution of the paper is benefitting transport planners and 
policy makers by providing a decision making process to integrate AHP-based ranking methods into selection of traffic control tool. The following some results are also reached in this work.

$\checkmark$ Flight time is the most important factor. With the increase of flight time, the usage of the drone in the sustainable traffic manegment applications will increase.Camera is weighted as the second most significant factor. The usage of drones targets to achieve the real-time data and visualization in traffic control.

$\checkmark$ Other important two factor are flight distance and flight speed.

$\checkmark$ Despite drones are already aimed to use in smart cities and in smart transportation and sustainable traffic control, flight time, flight distance and flight speed are not high. Today, traffic controllers prefer drones for small applications. So, it is rather crucial to improve these criteria for future traffic control and management applications.

$\checkmark$ Due to drones are practical options, policy-makers should maintain to support drones.

$\checkmark$ More incentive policies can be given to drones, due to provide flexible applications to be smart cities and sustainable transportation for near future.

\subsection{Future study}

The proposed methodology in the present study can be used many transportation planning problems such as transportation mode selection, route selection, clean vehicle selection, network optimization, personnel selection etc. The present study focused only on significant specific criteria of drones and to consider to these criteria for selection of drone vehicles. The number of evaluation criteria can be increased to improve the accuracy of the results. Especially, it can be used quantitative criteria such as trust, manoeuvrability, ergonomics, human factors, security systems, tactical capability, performance. Besides, fuzzy MCDM such as fuzzy AHP, fuzzy TOPSIS, MOORA, VIKOR methods can be used under fuzzy environment. In this study, adverse weather conditions are not taken into account. In future studies, resistance to bad weather conditions can be considered as a criterion. In addition to, mathematical models such as goal programming can establish as hybrid with MCDM under the budget and mission goals in future studies. The implemented decision making process for selection of drones in this study with the aim of traffic control and monitoring, can be also used in areas of agriculture, environmental protection, tourism support, large-scale disaster management, military mission and civil engineering applications.

\section{Declarations}

Ethics approval and consent to participate: The study does not require an ethics approval and consent to participate.

Availability of data and materials: The data that support the findings of this study are available from the corresponding author upon reasonable request

Competing interests: There is no conflict of interest in the study.

Funding: This research received no external funding. 
Authors' contributions: Data curation, M.H.; Methodology, M.H.; Writing—original draft preparation, M.H. and T.E.; Validation, T.E.

Consent to Publish: Not applicable

\section{References}

Al-Madani, B., Svirskis, M., Narvydas, G., Maskeliūnas, R., \& Damaševičius, R. (2018). Design of Fully Automatic Drone Parachute System with Temperature Compensation Mechanism for Civilian and Military Applications. Journal of Advanced Transportation, 2018.

Ameen, R. F. M., \& Mourshed, M. (2019). Urban sustainability assessment framework development: The ranking and weighting of sustainability indicators using analytic hierarchy process. Sustainable Cities and Society, 44, 356-366.

Awasthi, A., Omrani, H., \& Gerber, P., (2018). Investigating ideal solution based multicriteria decision making techniques for sustainability evaluation of urban mobility projects. Transportation Research Part A: Policy and Practice, 116, 247-259.

Alkharabsheh, A., Moslem, S., Oubahman, L., \& Duleba, S. (2021). An Integrated Approach of MultiCriteria Decision-Making and Grey Theory for Evaluating Urban Public Transportation Systems. Sustainability, 13(5), 2740.

Barmpounakis, E. N., Vlahogianni, E. I., \& Golias, J. C. (2016). Unmanned Aerial Aircraft Systems for transportation engineering: Current practice and future challenges. International Journal of Transportation Science and Technology, 5(3), 111-122.

Barmpounakis, E., \& Geroliminis, N. (2020). On the new era of urban traffic monitoring with massive drone data: The pNEUMA large-scale field experiment. Transportation Research Part C: Emerging Technologies, $111,50-71$.

Broniewicz, E., \& Ogrodnik, K. (2020). Multi-criteria analysis of transport infrastructure projects. Transportation research part D: transport and environment, 83, 102351.

Bakioglu, G., \& Atahan, A. O. (2021). AHP integrated TOPSIS and VIKOR methods with Pythagorean fuzzy sets to prioritize risks in self-driving vehicles. Applied Soft Computing, 99, 106948.

Bertrand, S., Raballand, N., \& Viguier, F. (2018, June). Evaluating Ground Risk for Road Networks Induced by UAV Operations. In 2018 International Conference on Unmanned Aircraft Systems (ICUAS) (pp. 168176). IEEE.

Brauers, W. K., \& Zavadskas, E. K. (2006). The MOORA method and its application to privatization in a transition economy. Control and cybernetics, 35, 445-469.

Broniewicz, E., \& Ogrodnik, K. (2020). Multi-criteria analysis of transport infrastructure projects. Transportation Research Part D: Transport and Environment, 83, 102351.

Buwana, E., Hasibuan, H. S., \& Abdini, C. (2016). Alternatives selection for sustainable transportation system in Kasongan City. Procedia-Social and Behavioral Sciences, 227, 11-18. 
Büyüközkan, G.; Feyzioğlu, O.; Göçer, F. Selection of sustainable urban transportation alternatives using an integrated intuitionistic fuzzy Choquet integral approach. Transp. Res. Part D Transp. Environ. 2018, 58, 186-207.,

Chow, J. Y. J. (2016). Dynamic UAV-based traffic monitoring under uncertainty as a stochastic arcinventory routing policy. International Journal of Transportation Science and Technology, 5, 167-185.

Coifman, B.; McCord, M.; Mishalani, R.G.; Iswalt, M.; Ji, Y. Roadway traffic monitoring from an unmanned aerial vehicle. IEE Proc. Intell. Transp. Syst. 2006, 153, 11-20.

Congress, S. S., Puppala, A. J., \& Lundberg, C. L. (2018). Total system error analysis of UAV-CRP technology for monitoring transportation infrastructure assets. Engineering geology, 247, 104-116.

De Melo, R. R. S., Costa, D. B., Álvares, J. S., \& Irizarry, J. (2017). Applicability of unmanned aerial system (UAS) for safety inspection on construction sites. Safety science, 98, 174-185.

Deng, L., Mao, Z., Li, X., Hu, Z., Duan, F., \& Yan, Y. (2018). UAV-based multispectral remote sensing for precision agriculture: A comparison between different cameras. ISPRS journal of photogrammetry and remote sensing, 146, 124-136.

Deveci, M., Canıtez, F., \& Gökaşar, I. (2018). WASPAS and TOPSIS based interval type-2 fuzzy MCDM method for a selection of a car sharing station. Sustainable Cities and Society, 41, 777-791.

Doğan, E., \& Akgüngör, A. P. (2016). Optimizing a fuzzy logic traffic signal controller via the differential evolution algorithm under different traffic scenarios. Simulation, 92(11), 1013-1023.

d'Oleire-Oltmanns, S., Marzolff, I., Peter, K. D., \& Ries, J. B. (2012). Unmanned aerial vehicle (UAV) for monitoring soil erosion in Morocco. Remote Sensing, 4(11), 3390-3416.

Elloumi, M., Dhaou, R., Escrig, B., Idoudi, H., Saidane, L. A., \& Fer, A. (2019, October). Traffic Monitoring on City Roads Using UAVs. In International Conference on Ad-Hoc Networks and Wireless (pp. 588-600). Springer, Cham.

Freeman, B. S., Al Matawah, J. A., Al Najjar, M., Gharabaghi, B., \& Thé, J. (2019). Vehicle stacking estimation at signalized intersections with unmanned aerial systems. International Journal of Transportation Science and Technology, 8(2), 231-249.

Gago, J., Douthe, C., Coopman, R., Gallego, P., Ribas-Carbo, M., Flexas, J., ... \& Medrano, H. (2015). UAVs challenge to assess water stress for sustainable agriculture. Agricultural water management, 153, 919.

Garcia-Aunon, P., Roldán, J. J., \& Barrientos, A. (2019). Monitoring traffic in future cities with aerial swarms: Developing and optimizing a behavior-based surveillance algorithm. Cognitive Systems Research, 54, 273-286.

Gür, Ş., Hamurcu, M., \& Eren, T. (2017). Ankara'da Monoray projelerinin analitik hiyerarşi prosesi ve 0-1 hedef programlama yöntemleri ile seçimi. Pamukkale Üniversitesi Mühendislik Bilimleri Dergisi, 23(4), 437-443.

Ham, Y., Han, K. K., Lin, J. J., \& Golparvar-Fard, M. (2016). Visual monitoring of civil infrastructure systems via camera-equipped Unmanned Aerial Vehicles (UAVs): a review of related works. Visualization in Engineering, 4(1), 1. 
627 Hamurcu and Eren (2020). Applications of the MOORA and TOPSIS Method for Decision of Electric 628 Vehicle in Public Transportation Technology. Transport (In press)

629 Hamurcu, M., \& Eren, T. (2020). Electric bus selection with multicriteria decision analysis for green 630 transportation. Sustainability, 12(7), 2777.

631 Hamurcu, M., \& Eren, T. (2020). Strategic planning based on sustainability for urban transportation: an 632 application to decision-making. Sustainability, 12(9), 3589.Hamurcu, M., \& Eren, T. (2018). Transportation 633 planning with analytic hierarchy process and goal programming. International Advanced Researches and 634 Engineering Journal, 2(2), 92-97.

635 Hamurcu, M., Alağaş, H. M., \& Eren, T. (2017). Selection of rail system projects with analytic hierarchy 636 process and goal programming. Sigma Journal of Engineering and Natural Sciences, 8(2), 291-302.

637 Hamurcu., M and Eren, T. (2019). Multicriteria Decision Making Based on Sustainability in The Selection 638 of UAV Applications for Smart Cities. 25th International Conference on Multiple Criteria Decision Making, 639 132-133, Istanbul, turkey.

640 Honkavaara, E., Saari, H., Kaivosoja, J., Pölönen, I., Hakala, T., Litkey, P., ... \& Pesonen, L. (2013). 641 Processing and assessment of spectrometric, stereoscopic imagery collected using a lightweight UAV 642 spectral camera for precision agriculture. Remote Sensing, 5(10), 5006-5039.

643 Hwang, C. L., \& Yoon, K. (1981). Multiple criteria decision making. Lecture Notes in Economics and 644 Mathematical Systems, 186, 58-191.

645 Jenkins, D. P. (2012). Using cognitive work analysis to describe the role of UAVs in military operations. 646 Theoretical Issues in Ergonomics Science, 13(3), 335-357.

647 Kanistras, K.; Martins, G.; Rutherford, M.J.; Valavanis, K.P. Survey of unmanned aerial vehicles (UAVs) 648 for traffic monitoring. In Handbook of Unmanned Aerial Vehicles; Springer: Dordrecht, The Netherlands, 649 2015; pp. 2643-2666.

650 Ke, R., Li, Z., Tang, J., Pan, Z., \& Wang, Y. (2018). Real-time traffic flow parameter estimation from UAV 651 video based on ensemble classifier and optical flow. IEEE Transactions on Intelligent Transportation 652 Systems, 20(1), 54-64.

653 Khan, M. A., Ectors, W., Bellemans, T., Janssens, D., \& Wets, G. (2018). Unmanned aerial vehicle-based 654 traffic analysis: A case study for shockwave identification and flow parameters estimation at signalized 655 intersections. Remote Sensing, 10(3), 458.

656 Khan, M. A., Ectors, W., Bellemans, T., Ruichek, Y., Janssens, D., \& Wets, G. (2018). Unmanned Aerial 657 Vehicle-based Traffic Analysis: A Case Study to Analyze Traffic Streams at Urban Roundabouts. Procedia 658 computer science, 130, 636-643.

659 Khan, M.A.; Ectors, W.; Bellemans, T.; Janssens, D.; Wets, G. UAV-Based Traffic Analysis: A Universal 660 Guiding Framework Based on Literature Survey. Transp. Res. Procedia 2017, 22, 541-550.

661 Khan, M.A.; Ectors,W.; Bellemans, T.; Janssens, D.;Wets, G. Unmanned Aerial Vehicle-Based Traffic 662 Analysis: A Methodological Framework for Automated Multi-Vehicle Trajectory Extraction. Transp. Res. 663 Rec. J. Transp. Res. Board 2017, 32, 25-33.

664 Kim, J., Kim, S., Ju, C., \& Son, H. I. (2019). Unmanned aerial vehicles in agriculture: A review of 665 perspective of platform, control, and applications. IEEE Access, 7, 105100-105115. 
Kim, S. J., Lim, G. J., Cho, J., \& Côté, M. J. (2017). Drone-aided healthcare services for patients with chronic diseases in rural areas. Journal of Intelligent \& Robotic Systems, 88(1), 163-180.

Kim, E., Hewings, G. J., \& Amir, H. (2017). Economic evaluation of transportation projects: An application of Financial Computable General Equilibrium model. Research in Transportation Economics, 61, 44-55.

Kumar, A., \& Anbanandam, R. (2019). Development of social sustainability index for freight transportation system. Journal of cleaner production, 210, 77-92.

Levi, Y., Bekhor, S., \& Rosenfeld, Y. (2019). A multi-objective optimization model for urban planning: The case of a very large floating structure. Transportation Research Part C: Emerging Technologies, 98, 85100.

Li, C. C., Zhang, G. S., Lei, T. J., \& GONG, A. D. (2011). Quick image-processing method of UAV without control points data in earthquake disaster area. Transactions of Nonferrous Metals Society of China, 21, s523-s528.

Li, C., Negnevitsky, M., Wang, X., Yue, W. L., \& Zou, X. (2019). Multi-criteria analysis of policies for implementing clean energy vehicles in China. Energy policy, 129, 826-840.

Li, M., Zhen, L., Wang, S., Lv, W., \& Qu, X. (2018). Unmanned aerial vehicle scheduling problem for traffic monitoring. Computers \& Industrial Engineering, 122, 15-23.

Liu, P., Chen, A. Y., Huang, Y. N., Han, J. Y., Lai, J. S., Kang, S. C., ... \& Tsai, M. H. (2014). A review of rotorcraft unmanned aerial vehicle (UAV) developments and applications in civil engineering. Smart Struct. Syst, 13(6), 1065-1094.

Lucic, M. C., Ghazzai, H., \& Massoud, Y. (2020). A Generalized Dynamic Planning Framework for Green UAV-Assisted Intelligent Transportation System Infrastructure. IEEE Systems Journal.

Luo, C., Miao, W., Ullah, H., McClean, S., Parr, G., \& Min, G. (2019). Unmanned aerial vehicles for disaster management. In Geological Disaster Monitoring Based on Sensor Networks (pp. 83-107). Springer, Singapore.

Mavi, R. K., Zarbakhshnia, N., \& Khazraei, A. (2018). Bus rapid transit (BRT): A simulation and multi criteria decision making (MCDM) approach. Transport Policy, 72, 187-197.

Manupati, V. K., Ramkumar, M., \& Samanta, D. (2018). A multi-criteria decision making approach for the urban renewal in Southern India. Sustainable Cities and Society, 42, 471-481.

Mohamed, N., Al-Jaroodi, J., Jawhar, I., Idries, A., \& Mohammed, F. (2018). Unmanned aerial vehicles applications in future smart cities. Technological Forecasting and Social Change, 119293.

Mota, R. L., Felizardo, L. F., Shiguemori, E. H., Ramos, A. C., \& Mora-Camino, F. (2014). Expanding small UAV capabilities with ANN: a case study for urban areas inspection. British Journal of Applied Science \& Technology, 4(2), 387.

Nassereddine, M., \& Eskandari, H., 2017. An integrated MCDM approach to evaluate public transportation systems in Tehran. Transportation Research Part A: Policy and Practice, 106, 427-439.

Onat, N.C.; Gumus, S.; Kucukvar, M.; Tatari, O. Application of the TOPSIS and intuitionistic fuzzy set approaches for ranking the life cycle sustainability performance of alternative vehicle technologies. Sustain. Prod. Consum. 2016, 6, 12-25. 
704 Opricovic, S., \& Tzeng, G. H. (2004). Compromise solution by MCDM methods: A comparative analysis

705 of VIKOR and TOPSIS. European journal of operational research, 156(2), 445-455.

706 Opricović, S.: Višekriterijumska optimizacija sistema u građevinarstvu, Građevinski fakultet, Beograd, $707 \quad 1998$

708 Oztaysi, B., Onar, S.C., Kahraman, C., Yavuz, M.: Multi-criteria alternative-fuel technology selection using 709 interval-valued intuitionistic fuzzy sets. Transp. Res. Part D Transp. Environ. 53, 128-148 (2017).

710 Özcan, E., Danışan, T., \& Eren, T. (2019). Hidroelektrik santralların en kritik elektriksel ekipman

711 gruplarının bakım stratejilerinin optimizasyonu için matematiksel bir model önerisi. Pamukkale Üniversitesi

712 Mühendislik Bilimleri Dergisi, 25(4), 498-506.

713 Papageorgiou, M., Kosmatopoulos, E., \& Papamichail, I. (2008). Effects of variable speed limits on 714 motorway traffic flow. Transportation Research Record, 2047(1), 37-48.

715 Patel, J. D., \& Maniya, K. D. (2015). Application of AHP/MOORA method to select wire cut electrical 716 discharge machining process parameter to cut EN31 alloys steel with brasswire. Materials Today: 717 Proceedings, 2(4-5), 2496-2503.

718 Puri, A. A Survey of Unmanned Aerial Vehicles(UAV) for Traffic Surveillance; Technical Report; 719 Department of Computer Science and Engineering, University of South Florida: Tampa, FL, USA, 2005.

720 Raj, A., \& Sah, B. (2019). Analyzing critical success factors for implementation of drones in the logistics 721 sector using grey-DEMATEL based approach. Computers \& Industrial Engineering, 138, 106118.

722 Rajak, S., Parthiban, P., \& Dhanalakshmi, R. (2016). Sustainable transportation systems performance 723 evaluation using fuzzy logic. Ecological Indicators, 71, 503-513.

724 Reshma, R., Ramesh, T., \& Sathishkumar, P. (2016, January). Security situational aware intelligent road 725 traffic monitoring using UAVs. In 2016 international conference on VLSI systems, architectures, 726 technology and applications (VLSI-SATA) (pp. 1-6). IEEE.

727 Ryan, A., Fitzpatrick, C., Christofa, E., \& Knodler Jr, M. (2020). Driver performance due to small unmanned 728 aerial system applications in the vicinity of roadways. Transportation Research Part F: Traffic Psychology 729 and Behaviour, 68, 118-131.

730 Saaty, T. L. (2008). Decision making with the analytic hierarchy process. International journal of services 731 sciences, 1(1), 83-98.

732 Sałabun, W., Palczewski, K., \& Wątróbski, J. (2019). Multicriteria approach to sustainable transport 733 evaluation under incomplete knowledge: Electric Bikes Case Study. Sustainability, 11(12), 3314.

734 Salvo, G., Caruso, L., \& Scordo, A. (2014). Urban traffic analysis through an UAV. Procedia-Social and 735 Behavioral Sciences, 111(February), 1083-1091.

736 Sarkar, B., \& Biswas, A. (2021). Pythagorean fuzzy AHP-TOPSIS integrated approach for transportation 737 management through a new distance measure. Soft Computing, 25(5), 4073-4089.

738 Sreenath, S., \& Panda, M. (2019, April). Traffic Counting and Turning Fraction Estimation using Vehicle739 to-UAV Co-operative communication. In 2019 3rd International Conference on Trends in Electronics and 740 Informatics (ICOEI) (pp. 675-681). IEEE. 

shared aerial drone videos for destination marketing. Journal of Travel \& Tourism Marketing, 36(7), 808822.

744 Sutheerakul, C., Kronprasert, N., Kaewmoracharoen, M., \& Pichayapan, P. (2017). Application of 745 unmanned aerial vehicles to pedestrian traffic monitoring and management for shopping streets. 746 Transportation research procedia, 25, 1717-1734.

747 Torres, M., Pelta, D. A., Verdegay, J. L., \& Torres, J. C. (2016). Coverage path planning with unmanned 748 aerial vehicles for 3D terrain reconstruction. Expert Systems with Applications, 55, 441-451.

749 Ullah, S., Kim, K. I., Kim, K. H., Imran, M., Khan, P., Tovar, E., \& Ali, F. (2019). UAV-enabled healthcare 750 architecture: Issues and challenges. Future Generation Computer Systems, 97, 425-432.

751 Un, D. (2014). World urbanization prospects: The 2014 revision, United Nations Department of Economics and Social Affairs, Population Division: New York, NY, USA.

754 optimization, Informatica 23 (1) (2012) 1-25 .

Wann-Ming Wey, Jhong-You Huang, 2018. Urban sustainable transportation planning strategies for livable City's quality of life, Habitat International, 82, 9-27. quality monitoring for sustainable systems via drone based technology. In 2016 IEEE International Conference on Information and Automation for Sustainability (ICIAfS) (pp. 1-5). IEEE.

Xu, Z., Yang, J., Peng, C., Wu, Y., Jiang, X., Li, R., ... \& Tian, B. (2014). Development of an UAS for postearthquake disaster surveying and its application in Ms7. 0 Lushan Earthquake, Sichuan, China. Computers \& Geosciences, 68, 22-30.

Yakıc1, E. (2016). Solving location and routing problem for UAVs. Computers \& Industrial Engineering, 102, 294-301.

Yang, J., Park, M. W., Vela, P. A., \& Golparvar-Fard, M. (2015). Construction performance monitoring via still images, time-lapse photos, and video streams: Now, tomorrow, and the future. Advanced Engineering Informatics, 29(2), 211-224. Regulations. Avrupa Bilim ve Teknoloji Dergisi, (16), 925-932.

Yu, C., Feng, Y., Liu, H. X., Ma, W., \& Yang, X. (2018). Integrated optimization of traffic signals and vehicle trajectories at isolated urban intersections. Transportation research part B: methodological, 112, 89112. 